\title{
Pathogenic and Molecular Characterization of Three Phomopsis Isolates from Peach, Plum, and Asian Pear
}

\author{
W. Uddin and K. L. Stevenson, Department of Plant Pathology, University of Georgia, Athens 30602; and R. A. \\ Pardo-Schultheiss and S. A. Rehner, Systematic Botany and Mycology Laboratory, USDA-ARS, B011A BARC- \\ WEST, Beltsville 20705
}

\begin{abstract}
Uddin, W., Stevenson, K. L., Pardo-Schultheiss, R. A., and Rehner, S. A. 1998. Pathogenic and molecular characterization of three Phomopsis isolates from peach, plum, and Asian pear. Plant Dis. 82:732-737.

Three isolates of Phomopsis, causing shoot blight of peach, shoot tissue necrosis of plum, or bud death of Hosui Asian pear, respectively, were evaluated for their pathogenicity on apple, pear, peach, and plum. Current year's shoots of 1-year-old Stayman Winesap apple, Barlett pear, Babygold-7 peach, and Bruce plum trees were inoculated with each isolate by wounding a bud and applying agar blocks bearing young hyphae. The length of cankers on shoots was measured 10,17 , and 24 days after inoculation. Cankers developed on shoots of all hosts inoculated with the peach isolate and on peach shoots inoculated with plum and Asian pear isolates. No cankers developed on apple, pear, or plum shoots inoculated with plum and Asian pear isolates. In the first experiment, 10 days after inoculation, the length of cankers on apple trees $(56.0 \mathrm{~mm}) \mathrm{in}-$ oculated with the peach isolate was not significantly different $(P \geq 0.05)$ from that on peach $(42.8 \mathrm{~mm})$, but was significantly greater than that on plum $(25.3 \mathrm{~mm})$ and pear $(13.1 \mathrm{~mm})$. The cankers on peach were significantly longer than those on pear, but not on plum. Cankers on all four hosts were significantly different from one another 17 and 24 days after inoculation. There was no significant difference between the length of cankers on peach shoots inoculated with plum and Asian pear isolates, and they were significantly smaller than those inoculated with the peach isolate. None of the control trees developed cankers. The three isolates differed in colony morphology, and appearance of conidiomata, conidiogenous cells, and $\alpha$-conidia on potato-dextrose agar. None of the isolates produced $\beta$-conidia in culture. Multi-locus DNA fingerprint analysis and internal transcribed spacer sequence comparisons revealed similarities between the plum and Asian pear isolates but a significant difference between these two and the peach isolate. The results indicate that the Phomopsis sp. that causes shoot blight of peach has the potential to cause disease on other stone and pome fruits, and peach may also be susceptible to isolates of Phomopsis from different tree fruit hosts.
\end{abstract}

Additional keywords: Malus, nucleotide sequences, pathogenicity, phylogenetics, Prunus, Pyrus

Phomopsis shoot blight of peach (Prunus persica (L.) Batsch) is an emerging problem in the peach-growing areas of the southeastern United States. This disease not only causes yield loss due to reduction of fruiting wood, but also a decline of trees in severely diseased orchards. The symptoms of peach shoot blight in the field develop initially as necrosis on current

Corresponding author: W. Uddin

E-mail:wxu2@psu.edu

American Type Culture Collection accession numbers: GLB06: 200995; GM12: 201293, and GAP08: 201292.

GenBank accession numbers: GLB06: U86406; GM12: U94898, and GAP08: U91617.

Accepted for publication: 14 March 1998.

Publication no. D-1998-0519-02R

(C) 1998 The American Phytopathological Society season's shoots centered around the vegetative and flower buds and the leaf petiole, usually in a zonate pattern with numerous pycnidia that form in the spring and produce cirri under certain humid conditions. The necrosis expands rapidly, disrupts the vascular tissues, and causes the shoot to wilt. Infrequently, necrosis of young shoot tissue may also originate from the growing tips of young shoots, but downward progression of the canker is limited to only a few centimeters below the buds $(5,9,19,20)$.

Shoot blight caused by Phomopsis spp. on other deciduous fruit trees such as apple, pear, and plum has not been a problem in this region. Although some species of Phomopsis caused blight of apple in Japan (3) and canker in north America (15), dieback and canker of pear in Japan $(8,11,16)$, and twig dieback of plum in England (12), it is unclear whether the Phomopsis sp. that causes shoot blight of peach in Georgia can cause similar diseases in pome and other stone fruits. The potential of this pathogen to infect other tree fruit species may have serious epidemiological consequences, because peach growers often maintain orchards with more than one tree fruit species or they may replace peach with another fruit species if Phomopsis shoot blight is severe. The infected fruit species could provide additional sources of inoculum for new infections. Isolates of a Phomopsis sp. collected from peach trees of various cultivars in three different geographic regions in Georgia and an orchard in Alabama were not different in their morphological characteristics, DNA fingerprints, nucleotide sequences, and virulence on peach shoots (20). It is unknown whether Phomopsis shoot blight is related to species of Phomopsis found in association with other fruit trees or whether peach trees are susceptible to these fungi. Because of the uncertainties in the taxonomy of Phomopsis spp. and the tremendous variations in the characteristics of conidiomata, conidiogenous cells, and the conidia (21), identification of these fungi to species is not practical and the biological and taxonomic relationship of the species of Phomopsis from peach, plum, and Asian pear is unknown. In order to understand the relationship between these fungi, molecular fingerprinting and sequencing of the nucleotides may provide important information. Therefore, this study was undertaken to determine (i) the pathogenicity of the peach shoot blight pathogen on pome and other stone fruits, (ii) the susceptibility of peach trees to species of Phomopsis associated with other deciduous fruit trees, and (iii) the taxonomic relationships among isolates of Phomopsis based on morphological and molecular characterization.

\section{MATERIALS AND METHODS}

Isolation of Phomopsis spp. from fruit trees. Phomopsis spp. were isolated from samples of blighted shoots of plum (Prunus domestica L., line BY8158-50) and shoots of Hosui Asian pear (Pyrus pyrifolia (N. L. Burm.) Nakai) with necrotic buds from Macon and Pierce counties, Georgia, respectively, in March 1995. The plum shoots were washed thoroughly 
in tap water and blotted dry. The leaves were removed and shoots were cut into 3$\mathrm{cm}$ segments containing both necrotic and healthy tissue, immersed in $10 \%$ ethanol for $1 \mathrm{~min}$, rinsed in sterilized distilled water, immersed in $0.5 \% \mathrm{NaOCl}$ for $3 \mathrm{~min}$, and blotted dry. Pieces of tissue, approximately 2 by 2 by $4 \mathrm{~mm}$ in size, were aseptically removed from the leading edge of necrotic zones under the bark and placed on acidified potato dextrose agar (PDA). After 7 days at room temperature (20 to $22^{\circ} \mathrm{C}$ ), hyphal tips of the fungi were transferred to PDA and maintained in an incubator at $20^{\circ} \mathrm{C}$ under continuous fluorescent light $\left(110 \mu \mathrm{E}^{-2} \mathrm{~s}^{-1}\right)$ for 21 days. Genera of isolates were then identified based on characters of the conidiomata, conidiogenous cells, and conidia. Fungi associated with the dead buds of Asian pear were isolated and identified in a similar manner. Tissue pieces were removed from the interface of necrotic and healthy areas between the dead buds and shoot tissue. After 7 days, young hyphal tips of the fungi were transferred to PDA and incubated as described above.

The peach isolate of Phomopsis, GLB06, was originally isolated from a diseased shoot of an 8-year-old Georgia Belle peach tree from an orchard in Hall County, Georgia in 1994, where peach shoot blight was severe. The pathogenicity of the peach isolate on peach has been demonstrated previously $(19,20)$. The isolates of Phomopsis and other fungi from the shoots of plum and the buds of Asian pear were identified based on their morphological and cultural characteristics on PDA $(18,21)$.

Preparation of inoculum and plant material. A single conidium from each of the stock cultures of Phomopsis isolates from peach, plum, and Asian pear was transferred to PDA and incubated at $20^{\circ} \mathrm{C}$ under fluorescent light $\left(110 \mu \mathrm{E}^{-2} \mathrm{~s}^{-1}\right)$ for 12 days prior to inoculation. One-year-old trees of Stayman Winesap apple (Malus domestica Borkh.), Bartlett pear (Pyrus communis L.), Babygold-7 peach, and Bruce plum were planted in 11-liter plastic pots filled with a mixture of sterilized sand:soil:pine bark $(1: 1: 1 \mathrm{vol} / \mathrm{vol})$ and maintained in the greenhouse $\left(24 / 18^{\circ} \mathrm{C}\right.$, 12-h cycle). Trees were fertilized with water soluble 20-8.8-16.6 (N-P-K) fertilizer at the rate of $1.44 \mathrm{~g}$ per tree every 2 weeks.

Pathogenicity studies. Two studies were conducted in the greenhouse: a preliminary study of the pathogenicity of isolates of Phomopsis sp. from plum and Asian pear on peach, and a study to test the pathogenicity of isolates from peach, plum, and Asian pear on apple, pear, peach, and plum trees. In the preliminary study, six treatments (isolates) were arranged in a randomized complete block design with three replications. Three single conidial isolates of Phomopsis from plum (GM04,
GM05, and GM12) and Asian pear (GAP02, GAP05, and GAP08) were used to inoculate current year's shoots of Babygold-7 peach trees. The wound inoculation technique was similar to that described by Weingartner and Klos (23). The base of the

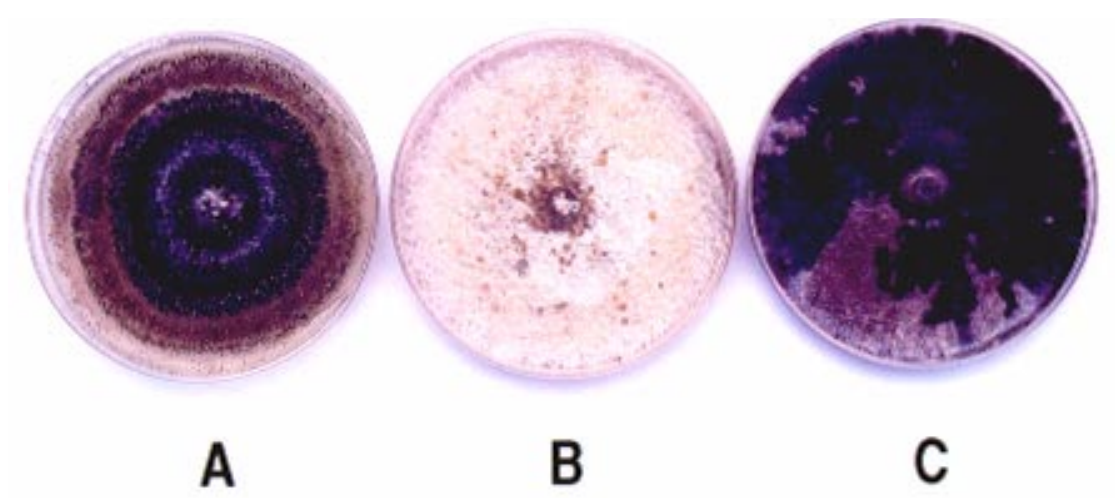

Fig. 1. Cultures of Phomopsis spp., 28 days old, from (A) peach, (B) plum, and (C) Asian pear on potato-dextrose agar.

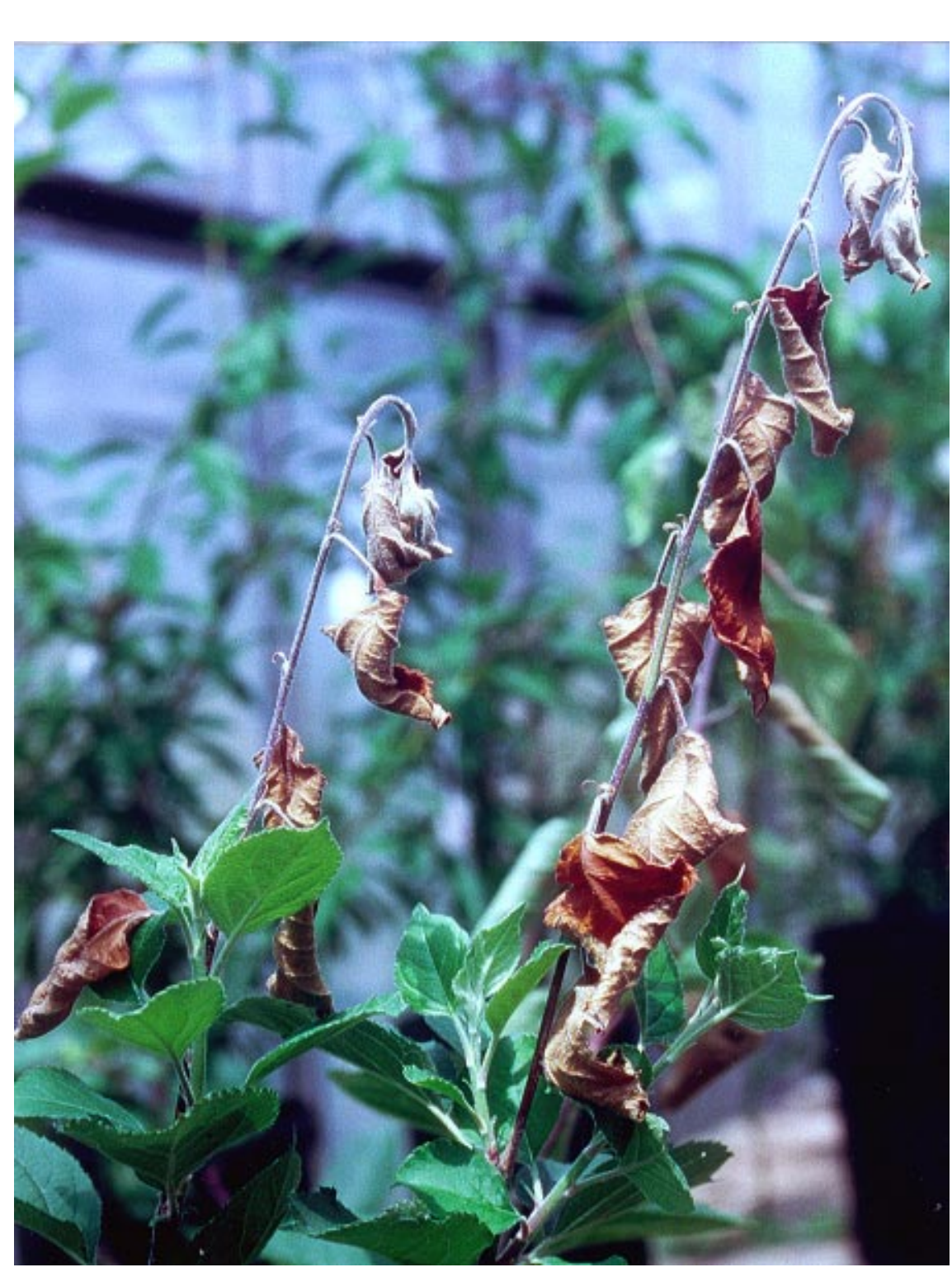

Fig. 2. Blighted shoot with shepherd's crook symptom on Stayman Winesap apple tree inoculated

with an isolate of Phomopsis (GLB06) originally isolated from peach with symptoms of shoot blight. petiole and the adjacent buds of the shoots were dissected horizontally using a scalpel, and the upper two-thirds of the buds and most of the petiole were removed. The cut area and the surrounding shoot surface was disinfested with $50 \%$ ethanol and blotted 
dry. A V-shaped incision was made at a $45^{\circ}$-angle to expose the tissue under the bark. An agar plug ( 2 by 2 by $2 \mathrm{~mm}$ ) containing young hyphae from a 12-day-old culture of a Phomopsis sp. was immediately placed in the incision and wrapped with moist sterilized cheese cloth and parafilm. Control trees were wounded in the same way and inoculated with blocks of sterile PDA. Two shoots on each tree were inoculated with each isolate. The parafilm and cheesecloth were removed 10 days after inoculation and disease development was evaluated by measuring the canker length on shoots. The fungi were reisolated from the inoculated shoots. The experiment was repeated following the same procedures.

The second study consisted of the treatment combinations of three isolates and a control, and four fruit species arranged in a 4 by 4 (pathogen by host) factorial design with three blocks. Two current year's shoots from each of the apple, pear, peach, and plum trees were inoculated with isolates of the species of Phomopsis from peach (GLB06), plum (GM12), and Asian pear (GAP08) following the same procedure as in the preliminary study. The control trees were also wounded and treated with blocks of sterile PDA. Disease development was evaluated 10, 17, and 24 days after inoculation by measuring the canker length on inoculated shoots. After the final assessment, inoculated shoots were removed from the trees and fungi reisolated.
The experiment was repeated following the same procedures.

Statistical analysis. Analysis of variance of canker length was performed for each experiment separately using the SAS General Linear Model procedure (release 6.10; SAS Institute, Cary, NC). Multiple comparisons of treatment means were made using Student-Newman-Keul's test $(\alpha=0.05)$.

DNA extraction, amplification, and sequence analysis. DNA was extracted from mycelia of the three monoconidial isolates of Phomopsis sp. (GLB06, GM12, and GAP08 ) used in pathogenicity tests. DNA extraction was performed according to the procedures described by Rehner and Samuels (13) and Rehner and Uecker (14).

The polymerase chain reaction (PCR) was applied for multi-locus fingerprinting to amplify DNA following the procedures described by Uddin et al. (20). Amplification products were separated electrophoretically on an agarose gel containing $1 \%$ Metaphor (FMC Bioproducts, Rockland, $\mathrm{ME})$ and $0.5 \%$ standard agarose in $1 \times$ trisborate-EDTA (TBE). The gel was stained with ethidium bromide, and the DNA was visualized with ultra-violet irradiation and photographed. Photographic negatives were examined visually and banding patterns compared. Similarity coefficients were obtained using the following formula: $S=2 N_{\mathrm{ab}} /\left(N_{\mathrm{a}}+N_{\mathrm{b}}\right)$, where $N_{\mathrm{a}}$ and $N_{\mathrm{b}}$ represent the total number of fragments for the species compared and $N_{\mathrm{ab}}$ represents the number of fragments in common (24). Dendrograms were derived from cluster analysis using the SAHN clustering methods (NTSYS, Exeter Publishing, Ltd., Setauket, NY). ITS fragments were sequenced according to the procedures described by Uddin et al. (20).

\section{RESULTS}

Isolation and characterization of Phomopsis isolates. A Phomopsis sp. was the predominant fungus isolated from necrotic cambium tissues of the blighted plum shoots and the interface of dead buds and healthy shoot tissue of Asian pear. Other fungi isolated from the shoots included species of Pestalotiopsis, Fusarium, Epicoccum, Alternaria, and Cladosporium. Distinct differences in colony morphology such as color, texture, and fruiting (pycnidia) were observed between Phomopsis isolates from peach, plum, and Asian pear grown on PDA. Cultures of the peach isolate (GLB06) on PDA were creamy white when young ( $<1$ week old), and turned light brown with concentric rings over time (4 weeks) with profuse production of pycnidia. Cultures of the plum isolate (GM12) on PDA were white when young and creamy white on older cultures (4 to 6 weeks). Production of pycnidia in the plum isolates appeared to be slower and more scattered than the peach isolates. Cultures of the Asian pear isolate (GAP08) on PDA were white when young and grayish-white to gray on older

Table 1. Sizes of fungal structures of Phomopsis isolates from peach, plum, and Asian pear in 28-day-old cultures on potato dextrose agar

\begin{tabular}{|c|c|c|c|c|}
\hline \multirow[b]{2}{*}{ Phomopsis isolate } & \multirow[b]{2}{*}{ Source } & \multicolumn{3}{|c|}{ Length $\times$ width $(\mu \mathrm{m})^{\mathrm{z}}$} \\
\hline & & Conidioma & Conidiogenous cell & $\alpha$-conidium \\
\hline GLB06 & Georgia Belle Peach & $200-550 \times 160-350$ & $10-17.5 \times 1.25-2.5$ & $7.5-10 \times 2.5-3.75$ \\
\hline GM12 & Plum (BY8158-50) & $125-380 \times 125-290$ & $11-15 \times 1.0-2.25$ & $7.5-15.0 \times 1.25-3.0$ \\
\hline GAP08 & Hosui Asian Pear & $110-315 \times 95-235$ & $8.5-15.5 \times 2.0-3.0$ & $6.5-12.5 \times 2.5-4.5$ \\
\hline
\end{tabular}

${ }^{\mathrm{z}}$ Values represent 60 measurements per isolate.

Table 2. Mean canker length on shoots of Babygold-7 peach inoculated with isolates of Phomopsis from three fruit hosts

\begin{tabular}{|c|c|c|c|c|c|c|c|}
\hline \multicolumn{2}{|c|}{ Source of Phomopsis isolate } & \multicolumn{3}{|c|}{ Experiment $1^{y}$} & \multicolumn{3}{|c|}{ Experiment $2^{y}$} \\
\hline Fruit species & Cultivar/line & 10 & 17 & 24 & 10 & 17 & 24 \\
\hline Peach & Babygold-7 & $42.8 \mathrm{a}^{\mathrm{z}}$ & $50.7 \mathrm{a}$ & $55.5 \mathrm{a}$ & $29.1 \mathrm{a}$ & $40.8 \mathrm{a}$ & $52.7 \mathrm{a}$ \\
\hline Plum & BY8158-50 & $19.2 \mathrm{~b}$ & $24.5 \mathrm{~b}$ & $26.0 \mathrm{~b}$ & $9.1 \mathrm{~b}$ & $11.6 \mathrm{~b}$ & $16.0 \mathrm{~b}$ \\
\hline Asian pear & Hosui & $13.3 \mathrm{~b}$ & $19.2 \mathrm{~b}$ & $24.0 \mathrm{~b}$ & $6.2 \mathrm{~b}$ & $10.6 \mathrm{~b}$ & $15.4 \mathrm{~b}$ \\
\hline
\end{tabular}

y Days after inoculation.

${ }^{z}$ Canker length $(\mathrm{mm})$. Values are means of three replications (with two inoculation per replicate) per treatment. Means within each column followed by the same letter(s) are not significantly different according to Student-Newman-Keul's test $(\alpha=0.05)$.

Table 3. Mean canker length on shoots of fruit species inoculated with isolates of Phomopsis from blighted peach shoots

\begin{tabular}{|c|c|c|c|c|c|c|c|}
\hline \multirow[b]{2}{*}{ Fruit species } & \multirow[b]{2}{*}{ Cultivar } & \multicolumn{3}{|c|}{ Experiment $1^{y}$} & \multicolumn{3}{|c|}{ Experiment $2^{y}$} \\
\hline & & 10 & 17 & 24 & 10 & 17 & 24 \\
\hline Apple & Stayman Winesap & $56.0 \mathrm{a}^{\mathrm{z}}$ & $68.2 \mathrm{a}$ & $73.2 \mathrm{a}$ & $53.9 \mathrm{a}$ & $93.8 \mathrm{a}$ & $105.9 \mathrm{a}$ \\
\hline Peach & Babygold-7 & $42.8 \mathrm{ab}$ & $50.7 \mathrm{~b}$ & $55.5 \mathrm{~b}$ & $29.1 \mathrm{~b}$ & $40.8 \mathrm{~b}$ & $52.7 \mathrm{~b}$ \\
\hline Plum & Bruce & $25.3 \mathrm{bc}$ & $30.3 c$ & $35.7 \mathrm{c}$ & $22.0 \mathrm{~b}$ & $37.6 \mathrm{~b}$ & $41.1 \mathrm{c}$ \\
\hline Pear & Bartlett & $13.1 \mathrm{c}$ & $18.1 \mathrm{~d}$ & $24.8 \mathrm{c}$ & $10.7 \mathrm{c}$ & $16.3 \mathrm{c}$ & $29.7 \mathrm{~d}$ \\
\hline
\end{tabular}

${ }^{\mathrm{y}}$ Days after inoculation

${ }^{z}$ Canker length (mm). Values are means of three replications (with two inoculation per replicate) per treatment. Means within each column followed by the same letter(s) are not significantly different according to Student-Newman-Keul's test $(\alpha=0.05)$. 
cultures (4 to 6 weeks), with occasional development of sectors (dark gray) on cultures, and production of pycnidia was slower than the peach and plum isolates (Fig. 1). The $\alpha$-conidia in all three isolates were hyaline, fusiform, straight, aseptate, and frequently biguttulate, and were similar among all three isolates; however, some conidia were multiguttulate. None of the cultures developed $\beta$-conidia. The sizes of conidiomata, conidiogenous cells, and $\alpha-$ conidia varied among the three isolates, although the ranges of length and width for each isolate overlapped to some extent (Table 1).

Pathogenicity studies. In the preliminary study, cankers developed in all peach shoots inoculated with the isolates of Phomopsis from plum and Asian pear. There was no significant difference $(\alpha=0.05)$ in length of cankers caused by the six isolates of Phomopsis from plum or Asian pear 10 days after inoculation in the first (10.7 to $17.3 \mathrm{~mm}$ ) or second (15.2 to $19.0 \mathrm{~mm})$ experiment. The fungi were successfully reisolated from cankers on inoculated peach trees.

In the second study, the peach isolate caused cankers in all four fruit tree species; however, the plum and Asian pear isolates caused cankers on peach but not on apple, plum, or pear trees when inoculated. Cankers on peach trees caused by the plum and Asian pear isolates were significantly smaller than those caused by the peach isolate (Table 2). There were no significant differences in the length of cankers caused by isolates of plum and Asian pear. Isolates of Phomopsis from plum and Asian pear were readily reisolated from the inoculated peach trees. Neither the plum nor Asian pear isolate was recovered from inoculated apple, plum, or pear trees.

In the first experiment of the second study, canker length on apple inoculated with the peach isolate was significantly greater than that on plum and Asian pear 10 days after inoculation; however, there were no significant differences between cankers on apple and peach trees (Table 3). The length of cankers on peach was not significantly different from that on plum, but was significantly longer than that on pear. There were no significant differences in cankers on plum and pear. Cankers on apple shoots inoculated with the peach isolate expanded more rapidly than those on peach and, after 17 days, cankers on apple were significantly longer than those on peach. Cankers on peach shoots were significantly longer than those on plum, which were significantly longer than those

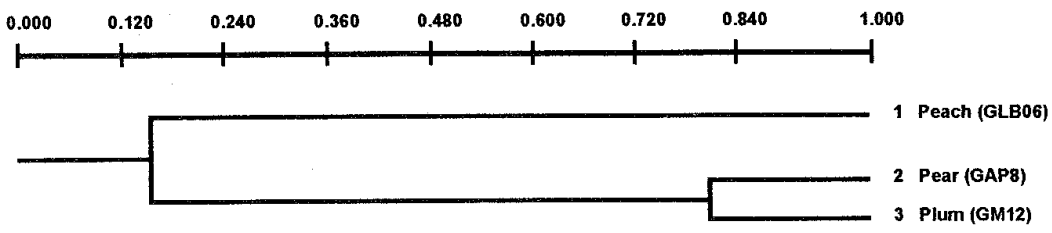

Fig. 3. Dendrogram showing the phylogenetic relationship among isolates of Phomopsis from peach, pear, and plum using the average combined similarity coefficient for primers $(\mathrm{GTG})_{5},(\mathrm{GGA})_{7}$, and M13 phage. Dendrograms were derived using the SAHN cluster analysis program in using NTSYS.

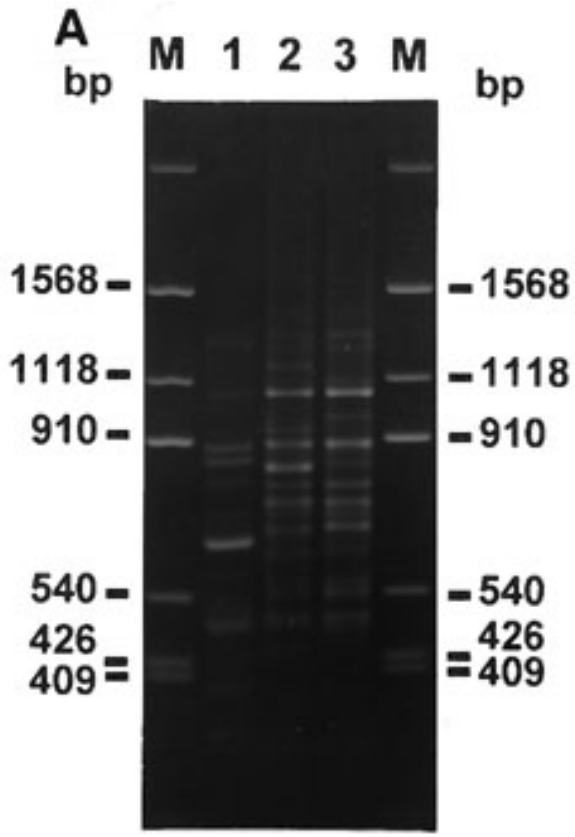

B

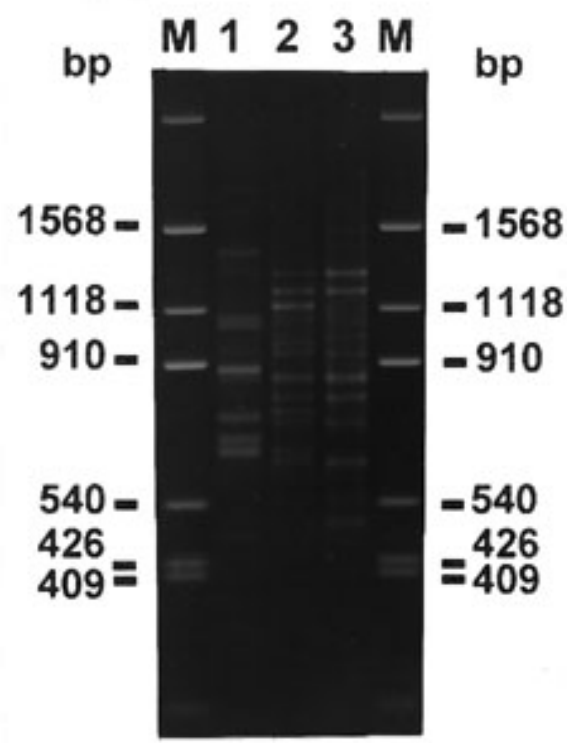

on pear. Cankers on all four fruit species showed the same pattern of development 24 days after inoculation, except that the cankers on pear did not differ significantly from those on plum.

Shoots of apple inoculated with the peach isolate wilted more rapidly than those of other fruit species (Fig. 2). Wilting of shoots of apple, peach, and plum inoculated with the peach isolate was first observed 14, 16, and 17 days after inoculation, respectively. Twenty-four days after inoculation, 66,50 , and $33 \%$ of the inoculated shoots of apple, peach, and plum, respectively, were completely necrotic from the point of inoculation to the shoot tip. None of the inoculated shoots of the pear trees were necrotic or wilted. No necrosis was observed on control trees of any of the fruit species inoculated with the sterile PDA agar plugs. Callus tissue developed at the wound sites of control shoots, effectively sealing off the exposed tissue. Reisolation from the inoculated trees yielded the same fungi that were used in inoculation. Fungi isolated from the callus tissue were identified as species of Pestalotiopsis, Penicillium, and Fusarium.

The pattern of canker development in the second experiment was similar to that in the first experiment. However, in the second experiment, there were no significant differences in cankers on peach and plum inoculated with the peach isolate, which were significantly longer than those on pear, 10 and 17 days after inoculation (Table 3). Cankers on all four fruit species were significantly different 24 days after inoculation. Cankers on apple were longest, followed by peach, plum, and pear. Wilting of shoots of apple, peach, and plum inoculated with the peach isolate was

Fig. 4. Ethidium bromide-stained gels of multi-locus amplification profiles for oligonucleotide primers (A) (GTG) $)_{5}$, (B) $(\mathrm{GGA})_{7}$, and (C) M13 phage.

Lane 1, 2, and 3 represent isolates of Phomopsis from peach (GLB06), pear (GAP08), and plum (GM12), respectively. Lane M is the pUC19 marker.

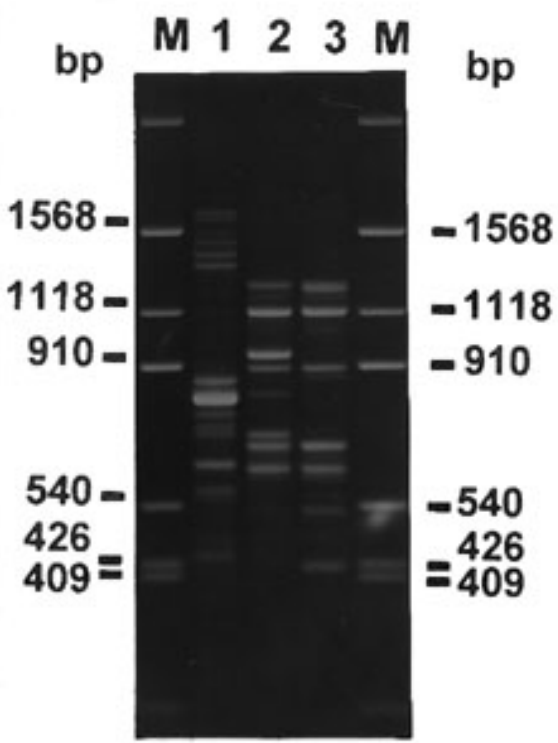


first observed 11, 19, and 23 days after inoculation, respectively. Twenty-four days after inoculation, 58, 42, and $8 \%$ of the inoculated shoots of apple, peach, and plum, respectively, were completely necrotic. No wilting was observed on pear shoots 24 days after inoculation. No necrosis or wilting was observed on control trees of any fruit species inoculated with sterile PDA. Callus tissue developed at wounded sites of the shoots on control trees, effectively sealing off the exposed tissue. Reisolation from the symptomatic shoots of inoculated trees yielded the same fungi that were used in inoculations, and callus tissue from all asymptomatic fruit trees yielded species of Penicillium and Fusarium.

DNA extraction, amplification, and sequence analysis. Multi-locus PCR amplifications generated with $(\mathrm{GTG})_{5}$, $(\mathrm{GGA})_{7}$, and the phage M13 core sequence oligonucleotide primers were conducted initially to determine whether any pair of strains shared randomly amplified markers. The expectation is that conspecific strains (strains derived from a single mating population or clones sharing a recent common ancestor) would share a significant number of markers in common, whereas interspecific comparisons would reveal little, if any, similarity in banding patterns.

Examination of the multi-locus amplification profiles (Figs. 3 and 4) revealed an average similarity coefficient of $0.81(S=$ $0.87,0.78$, and 0.78 , respectively) between the Asian pear and plum isolates, an average similarity coefficient of 0.21 ( $S=0.25$, 0.20 , and 0.18 , respectively) between isolates from peach and Asian pear, and an average similarity coefficient of $0.12(S=$ $0.25,0.11$, and 0.00 respectively) between isolates from peach and plum.

Results of ITS sequence comparisons (Fig. 5) were consistent with the results of multi-locus PCR analyses. Nucleotide sequences of the ITS region from Asian pear and plum isolates were identical. However, ITS sequences from both plum and Asian pear differed from the peach isolate by 28 substitutions and 5 alignment gaps (10 positions) in ITS 1 and by 11 substitutions and 2 alignment gaps (8 positions) in ITS2.

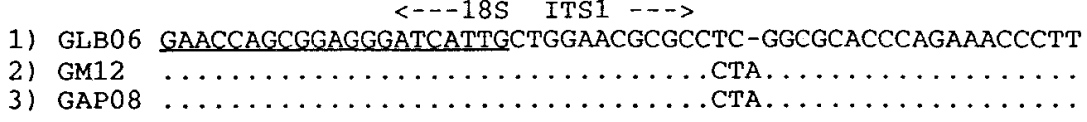

1) TGTGAACTTATACCTTACTGTTGCCTCGGCGCAGGCCGGCTCCCATCTGGGGGCCCCTCGT

2) $\ldots \ldots \ldots \ldots \ldots \ldots$ - $\ldots \ldots \ldots \ldots \ldots$ T. . T . TCTT . C- $--A \ldots \ldots$ T. TAC

3) $\ldots \ldots \ldots \ldots \ldots$ T. . . . . . TCTT. .C---A... T. TAC

1) TTC-TGACGAGGAGCAGGCTCGCCGGCGGCCAAGTTAACTCTTGTTTTTAATTTGAAACTC

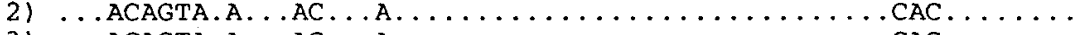

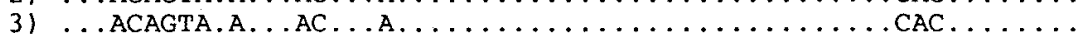
$<--$ ITS1 5.8S --->

1) TGAGAATAAAACATAAATGAATCAAAACTTTCAACAACGGATCTCTTGGTTCTGGCATCGA

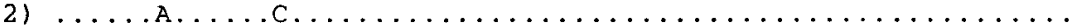

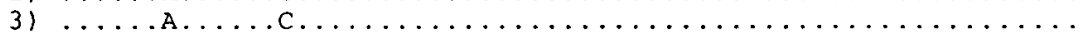

1) TGAAGAACGCAGCGAAATGCGATAAGTAATGTGAATTGCAGAATTCAGTGAATCATCGAAT

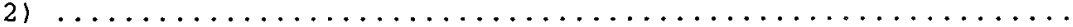

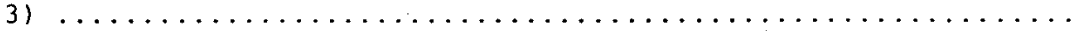

$<--5.8 S$

1) CTTTGAACGCACATTGCGCCCTCTGGTATTCCGGAGGGCATGCCTGTTCGAGCGTCATTTC

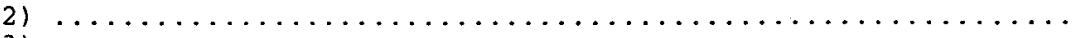

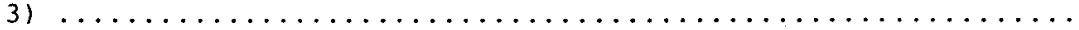

ITS2 -->

1) AACCCTCAAGCCTGGCTTGGTGATGGGGCACTGCCTTTGTGTAAAAGCGAAGGCAGGCCCT

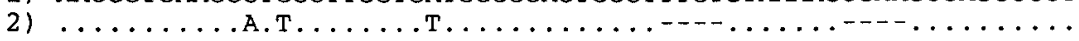

3) $\ldots \ldots \ldots \ldots$. $\ldots \ldots \ldots$ т. $\ldots \ldots \ldots \ldots \ldots \ldots$

1) GAAATTCAGTGGCGAGCTCGCCAGGACTCCGAGCGCAGTAGTTAAACCCTCGCTTTGGAAG

2) $\ldots \ldots$. . . . . . . . . . . . . . . . . . . . . . . . .

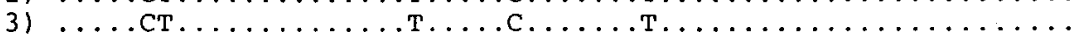

<-. ITS2 $28 \mathrm{~S} \ldots-\cdots$

1) GAC-TGGCGGTGCCCTGCCGTTAAACCCCCAACTCTTGAAAATTTGACCTCGGATCAGGTA

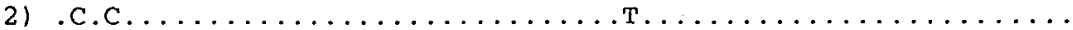

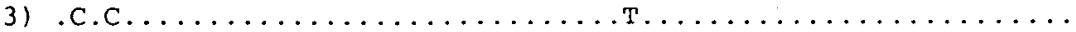

Fig. 5. Alignment of internal transcribed spacer sequences from three different isolates of Phomopsis from peach (GLB06), plum (GM12), and Asian pear (GAP08). Coding sequences of flanking 18S, $5.8 \mathrm{~S}$, and 28S RNA genes are underlined. Positions identical to reference sequence (GLB06) are indicated as dots, and alignment gaps are indicated as dashes.

\section{DISCUSSION}

This is the first report of the susceptibility of apple, plum, and pear to the pathogen causing shoot blight of peach. Although this pathogen has not been reported to cause disease on deciduous fruit trees other than peach in Georgia $(2,6,10,20)$, the ability of this fungus to infect pome and other stone fruits trees may become a concern for peach growers, especially where a variety of stone and pome fruit trees are planted in close proximity. Rapid development of cankers and wilting of shoots of apple trees in this study suggests that apple may be as susceptible as peach to this pathogen. Although Phomopsis mali (Schulzer \& Sacc.) Died. was reported to cause cankers or rough bark of apple in North America (15), it has not been a problem in apple orchards in Georgia.

It is evident from our study that the isolate of Phomopsis that causes shoot blight of peach in Georgia is not host-specific. Wide host ranges have also been documented for other species of Phomopsis $(1,4,17)$, and Rehner and Uecker reported that several species of Phomopsis are not restricted by host and are capable of infecting taxonomically unrelated host genera (14). Our results provide an indication that the species of Phomopsis that causes shoot blight of peach also has a wide host range.

In Japan, Sakuma et al. reported that dieback of European pear caused by Diaporthe tanakae Kobayashi \& Sakuma (anamorph Phomopsis tanakae) was often confused with fire blight because both diseases exhibit similar symptoms of a scorched appearance and the characteristic shepherd's crook (16). However, they indicated that despite these similarities, these diseases could still be discerned if the symptoms were examined carefully. They noted that wilting of the leaves and shoots results from expansion of the canker that disrupts vascular tissues, but unlike those of trees affected by fire blight, veins and petioles did not turn black. Additionally, horn-like cirri develop on shoots infected by $P$. tanakae under warm and humid conditions, whereas amorphous bacterial ooze or streaks occur on the shoots infected by Erwinia amylovora.

Shoots of apple trees inoculated with the peach shoot blight pathogen showed disease symptoms similar to that of fire blight caused by E. amylovora (Fig. 2). Fire blight of apple is quite prevalent in Georgia in most years, and is routinely diagnosed in the field based on the symptomatology, which includes blighted blossoms and shoots with a shepherd's crook appearance (10). In our study, symptoms of shoot blight of apple caused by Phomopsis spp. were not easily distinguished from those of fire blight. Symptoms in inoculated apple trees, such as marginal necrosis and shriveling or cupping of leaves, closely resemble symptoms of fire blight in systemically 
infected leaves through the supporting shoots of apple (7). Development of these symptoms in the greenhouse study warrants careful scouting of apple orchards in Georgia where, in the past, blighting of shoots has been attributed to fire blight. Accurate diagnosis of blighted shoots from affected orchards will be necessary to determine whether observed shoot blight problems are, in fact, due to infection by $E$. amylovora or Phomopsis spp.

Although no cankers or shoot blight symptoms developed on plum trees inoculated with plum isolates, development of cankers and shoot blight symptoms on plum trees inoculated with the peach isolate was similar to shoot blight symptoms on source trees (BY8158-50) of the plum isolate and the symptoms of Phomopsis shoot blight observed on peach in Georgia orchards. Barlett pear did not appear to be as susceptible as peach and plum to infection by the peach shoot blight pathogen in the pathogenicity study. Failure of the peach isolate to cause necrotic or scorched leaves or blighted shoots in inoculated pear trees may have been due to slower growth of the fungus and slower canker development in the shoot (Table 2). A period of 24 days may not have been long enough to cause disruption of vascular tissue.

The isolates of Phomopsis from plum and Asian pear were pathogenic on peach trees; however, they did not cause disease on plum and pear trees. These two isolates were similar in virulence on peach, but were not as virulent as the peach isolate. Inability of these isolates to cause disease on shoots of plum and pear trees may have been due to the particular species or cultivar used as test trees or unsuitable inoculation or environmental conditions. Disease symptoms on samples of Asian pear shoots appeared to be limited to necrotic buds, with little or no expansion of necrosis into stem tissues, providing some evidence to support the latter hypothesis. To determine conclusively whether the isolates are pathogenic on the hosts that they were originally isolated from, inoculation of trees of the same species or cultivar from which they were originally isolated will be required. Although the plum and Asian pear isolates did not cause disease on plum and pear trees, respectively, further studies, including more extensive field surveys and pathogenicity tests on different species and cultivars of stone and pome fruits, would provide important information to further understand the diversity and host range of the species of Phomopsis associated with deciduous fruit trees in Georgia.

Although differences in morphological characteristics were observed among Phomopsis isolates from different hosts (Table
1), due to the variation in measurements this information is of little practical use in determining taxonomic relationships among species (21). Results of molecular studies provided more reliable evidence of the phylogenetic relationships among Phomopsis isolates tested. The close similarity in multi-locus amplification profiles and identity in ITS sequence between the plum and Asian pear isolates suggests they are conspecific or closely related species. The different fingerprint pattern of the peach isolate from those of plum and Asian pear isolates and the divergent ITS sequence indicates the peach isolate appears to be a different species of Phomopsis. The sequence divergence between these two sets of isolates are consistent with differences among species in other taxonomic groups of fungi (14).

The observed morphological characters in vitro are insufficient for discriminating the peach, plum, and Asian pear isolates and uninformative for determining whether these isolates belong either to a previously described species or an unknown species. The inadequacy of morphological characters for species identification in Phomopsis has been noted elsewhere (22). Although it is not feasible to assign a species identification for these three isolates, the relative ease of isolate identification with molecular characters could facilitate further progress in understanding the biology and host range of Phomopsis spp. and the epidemiology of shoot blight of deciduous fruit trees. Determination of relative virulence on peach compared to the highly virulent peach isolate may also be important for understanding the diversity of the species of Phomopsis in nature and their potential impact on peach production.

\section{ACKNOWLEDGMENTS}

We thank D. Denney, M. Scott, and C. Laster for their assistance in the laboratory and greenhouse experiments, and J. Plaskowitz for his assistance with Figure 4.

\section{LITERATURE CITED}

1. Brayford, D. 1990. Variation in Phomopsis isolates from Ulmus species in the British Isles and Italy. Mycol. Res. 94:691-697.

2. Farr, D. F., Bills, G. F., Chamuris, G. P., and Rossman, A. Y. 1989. Fungi on Plants and Plant Products in the United States. APS Press, St. Paul, MN.

3. Fujita, K., Sugiki, T., and Matsunaka, K. 1988. Apple blight caused by Diaporthe tanakae in Aomori Prefecture. (In Japanese; English summary) Pages 17-35 in: Aomori Field Crops Hortic. Exp. Stn. Bull. 6.

4. Hahn, G. G. 1943. Taxonomy, distribution, and pathology of Phomopsis occulata and $P$. juniperovora. Mycologia 35:112-129.

5. Hendrix, F. F. 1989. Phomopsis bud and twig blight of peach. (Abstr.) Phytopathology 79:1154.

6. Hendrix, F. F., Copes, W. E., Horton, D. L.,
Jackson, J. J., MacDonald, G. E., Ferree, M. E., and Myers, S. C. 1996. Georgia Apple Pest Management and Production Guide. Coop. Ext. Serv. Univ. Georgia.

7. Jones, A. I., and Aldwinckle, H. S. 1990. Compendium of Apple and Pear Diseases. APS Press, St. Paul, MN.

8. Kobayashi, T., and Sakuma, T. 1982. Materials for the fungus flora of Japan. Trans. Mycol. Soc. Jpn. 23:37-40

9. Latham, A. J., Morgan-Jones, G., and Campbell, H. L. 1991. Phomopsis dieback of peach shoots in Alabama. Plant Dis. 74:426.

10. McVay, J. R., Walgenbach, J. F., Sikora, E. J., and Sutton, T. 1995. A Grower's Guide to Apple Insects and Diseases in the Southeast. Ala. Coop. Ext. Serv. Circ. No. ANR 838.

11. Nakatani, F., Hiraragi, T., and Sekizawa, H. 1984. Studies on the canker of pear caused by Diaporthe tanakae Kobayashi et Sakuma. Pages 47-70 in: Iwate Hortic. Exp. Stn. Bull. 5.

12. Ogawa, J. M., Zehr, E. I., Bird, G. W., Ritchie, D. F., Uriu, K., and Uyemoto, J. K. 1995. Compendium of Stone Fruit Diseases. APS Press, St. Paul, MN.

13. Rehner, S. A., and Samuels, G. J. 1994. Taxonomy and phylogeny of Gliocladium analyzed from the nuclear large subunit ribosomal DNA sequences. Mycol. Res. 98:625634.

14. Rehner, S. A., and Uecker, F. A. 1994. Nuclear ribosomal internal transcribed spacer phylogeny and host diversity in the Coelomycete. Can. J. Bot. 72:1666-1674

15. Roberts, J. W. 1913. The "rough bark" disease of Yellow Newtown apple. U. S. Dep. Agric. Bur. Plant Ind. Bull. 280.

16. Sakuma, T., Batra, L. R., Nakatani, F., and Sawamura, K. 1982. European pear die-back (Diaporthe sp.) in Japan and its comparison with pear fire blight (Erwinia amylovora) Pages 79-89 in: Bull. Fruit Tree Res. Stn. (Morioka, Jpn.) Ser. C9.

17. Schoeneweiss, D. F. 1969. Susceptibility of evergreen hosts to the juniper blight fungus, Phomopsis juniperovora, under epidemic conditions. J. Amer. Soc. Hortic. Sci. 94:609611.

18. Sutton, B. C. 1980. The Coelomycetes. Commonwealth Mycological Institute, Kew, Surrey, United Kingdom.

19. Uddin, W., and Reynolds, K. L. 1995. Phomopsis shoot blight of peach: Pathogenicity and influence of temperature on disease development. Phytopathology 85:1127.

20. Uddin, W., Stevenson, K. L., and PardoSchultheiss, R. A. 1997. Pathogenicity of a species of Phomopsis causing a shoot blight on peach in Georgia and evaluation of possible infection courts. Plant Dis. 80:983-989.

21. Uecker, F. A. 1988. A world list of Phomopsis names with notes on nomenclature, morphology and biology. Mycologia Memoir No. 13. Cramer Publishers, Berlin.

22. van der Aa, H. A., Noordeloos, M. E., and de Gruyter, J. 1990. Species concepts in some larger genera of the Coelomycetes. Stud. Mycol. 32:3-19.

23. Weingartner, D. P., and Klos, E. J. 1975. Etiology and symptomatology of canker and dieback diseases on highbush blueberries caused by Godronia (Fusicoccum) cassandrae and Diaporthe (Phomopsis vaccinii). Phytopathology 65:105-110.

24. Wetton, J. H., Carter, R. E., Parkin, D. T., and Walters, D. 1987. Demographic study of a wild sparrow population by DNA fingerprinting. Nature 327:147-149. 